\title{
A CERTIFICAÇÃO DE PRODUTOS ORCÂNICOS E SUA CREDIBILIDADE ENTRE OS CONSUMIDORES
}

\section{LIZANDRA ARIANE MACHADO DE CASTRO}

Mestranda em Administração, Universidade de São Paulo - USP, Brasil. lizandra.castro@usp.br

\section{SUSANA SALES DA SILVA CAMPOS}

Mestranda em Administração, Universidade de São Paulo - FEA-USP, Brasil. susanasalessilva@gmail.com

\section{REJANE DA SILVA VIANA}

Doutoranda em Administração, Universidade de São Paulo - FEA-USP, Brasil.

rejaneviana@yahoo.com.br

\section{Bernadete de LOURDES MARINHO GRANDOLPHO}

Doutora em Administração, Universidade de São Paulo - USP, Brasil.

Professora em Administração. Universidade de São Paulo - USP, Brasil.

marinhoy@usp.br

\section{Resumo}

0 presente trabalho apresenta o resultado de uma pesquisa que teve o intuito de identificar o grau de compreensão dos consumidores acerca dos selos de certificação de produtos orgânicos. Sendo um segmento de consumo crescente e com grande apelo para a saúde da população e do planeta, a garantia de cultivo correto vem do selo de certificação. A metodologia utilizada teve abordagem quantitativa, e a coleta de dados foi feita por survey, com uma amostra inicial de 194 respondentes. A amostra final compreendeu 120 respostas, que foram analisadas por meio do software Stata-SE. Os resultados apontaram que, tanto os consumidores que compraram produtos orgânicos apenas uma vez, quanto aqueles que consomem frequentemente esses produtos, são igualmente capazes de reconhecer selos de certificação orgânica. Além disso, os consumidores que buscam o selo de certificação na embalagem dos produtos são os que mais acreditam em seus benefícios.

Palavras-chave: produtos orgânicos, selo de certificação, pesquisa quantitativa. 


\title{
THE CERTIFICATION OF ORGANIC PRODUCTS AND ITS CREDIBILITY AMONG CONSUMERS
}

\begin{abstract}
The paper presents the results of a research carried out to identify consumers' degree of understanding of the certification stamps of organic products. Being a growing consumer segment, with a great appeal for the population and the planet's health, the guarantee of correct cultivation comes from the certification seal. The methodology had a quantitative approach and we collected data through a survey, with an initial sample of 194 respondents. The final sample contained 120 responses, which we analyzed with the support of Stata-SE version 12 software. The results showed that both consumers that bought organic products once and those who buy them often are equally able to recognize organic certification seals. In addition, consumers that look for the certification seal in the products' package are the ones that most believe in their benefits.
\end{abstract}

Keywords: organic products, certification seal, quantitative research.

\section{LA CERTIFICACIÓN DE PRODUCTOS ORGÁNICOS Y SU CREDIBILIDAD ENTRE LOS CONSUMIDORES}

\begin{abstract}
Resumen
El presente trabajo presenta el resultado de una investigación realizada con el fin de identificar el grado de comprensión de los consumidores acerca de los sellos de certificación de productos orgánicos. Siendo un segmento de consumo creciente y con gran atractivo para la salud de la población y del planeta, la garantía del cultivo correcto viene del sello de certificación. La metodología utilizada tuvo un abordaje cuantitativo siendo el procedimiento de recolección de datos hecho con survey dentro de una muestra inicial de 194 respondedores. La muestra final contenía 120 respuestas que se analizaron con el soporte del software Stata-SE. Los resultados apuntaron que tanto los consumidores que compraron productos orgánicos sólo una vez y los que consumen a menudo, son capaces de reconocer sellos de certificación orgánica. Además, consumidores que buscan el sello de certificación en el embalaje de los productos son los que más creen en sus beneficios.
\end{abstract}

Palabras clave: productos orgánicos, sello de certificación, investigación cuantitativa. 


\section{INTRODUÇÃO}

A busca da saúde e bem-estar introduziu novas tendências de consumo. A preocupação com as novas gerações, e até mesmo por interesse próprio, fez com que as pessoas passassem a procurar alternativas alimentícias com quantidade e qualidade ao mesmo tempo, como os produtos orgânicos (Solomon, 2011).

Para Trevizan e Casemiro (2009), em uma sociedade que se considere sustentável, o comércio de produtos orgânicos torna-se uma via de produção. Por isso, vários estudos têm sido realizados com o intuito de examinar a percepção do consumidor sobre os produtos orgânicos (Lima-Filho \& Quevedo-Silva, 2012), e quais os aspectos motivadores da compra desses produtos (Francisco, Moura, Zanon \& Marinho, 2009; Albuquerque, Silva, Costa \& Santos, 2013.

Nesse contexto, o consumidor deve estar atento ao que está comprando e levando para casa. Assim, surgem algumas questões: Como identificar se os produtos adquiridos pelos clientes são realmente considerados orgânicos? O modo de fabricação dos produtos orgânicos garante que os consumidores estão comprando algo de qualidade e livre de agrotóxicos? Há algum mecanismo oficial que garanta que o processo de produção dos orgânicos está sendo corretamente realizado?

A certificação de produtos orgânicos é necessária para informar aos consumidores que estão comprando um produto que foi fabricado de modo sustentável, e sem o uso de agrotóxicos e sementes geneticamente modificadas, de acordo com o Ministério da Agricultura, Pecuária e Abastecimento - Mapa (Mapa, 2018). Além dessas características, certificadoras devidamente credenciadas pelo Mapa observam ainda outros aspectos que garantem aos consumidores que os produtos orgânicos possuem os requisitos necessários para comercialização, sendo o selo orgânico a representação dessa garantia na embalagem do produto (Mapa, 2018).

Segundo dados do Mapa, o número de agricultores com certificação orgânica dobrou em oito anos. O mercado de produtos orgânicos expande-se cada vez mais, e os consumidores se tornam cada vez mais exigentes quanto aos produtos que adquirem. A decisão de compra de produtos orgânicos pode envolver, assim, outros fatores que não sejam a preocupação com a saúde ou com o meio ambiente. Rodrigues, Dalmarco, Aoqui e Marinho (2016) apontaram o selo de certificação como um dos fatores para o consumo consciente.

Diante do exposto, a pergunta de pesquisa foi assim definida: Qual a influência do selo de certificação orgânica sobre a decisão de compra dos consumidores? Para responder a esta pergunta, foram traçados os seguintes objetivos específicos: (a) Identificar se os consumidores sabem o que é um selo de certificação orgânica; (b) Verificar em que medida o selo de certificação em produtos orgânicos é decisivo no momento da compra; e (c) Enumerar os motivos que levam os consumidores a comprar produtos orgânicos certificados.

Para cumprir os objetivos da pesquisa, a próxima seção apresenta a revisão de literatura sobre o tema; na terceira seção são delineados os procedimentos metodológicos; na quarta é apresentada a análise e discussão dos resultados; e, por fim, a quinta seção descreve as conclusões.

\section{REFERENCIAL TEÓRICO}

\section{COMPORTAMENTO DO CONSUMIDOR E O PROCESSO DE DECISÃO DE COMPRA}

Os profissionais de marketing estão cada vez mais empenhados em buscar meios que auxiliem na satisfação das necessidades dos consumidores; para isso, são necessários estudos na área de administração de marketing, que abordem o comportamento dos consumidores, incluindo seus desejos, e mostrem como tomam suas decisões de compra (Sheth, Mittal \& Newman, 2001).

0S, Organizações e Sustentabilidade, 8(1), p. 92-107, Londrina, PR, jan./jun. 2020.

ISSN 2318-9223, http://www.uel.br/revistas/uel/index.php/ros/issue/view/1634/showToc 
Solomon (2002) considera que a finalidade das empresas é satisfazer as necessidades dos consumidores. E, para que isso ocorra, é preciso compreender quais são os interesses de consumo dos clientes. Para Kotler (1998), é necessário realizar o monitoramento da performance dos concorrentes.

Para Blackwell, Miniard e Engel (2005), abordar o comportamento do consumidor é entender os motivos pelos quais as pessoas compram; afinal, quando se entendem as razões que levam os consumidores a adquirir determinados produtos e serviços, torna-se mais simples a criação de estratégias para influenciá-los.

Diversos autores desenvolveram pesquisas para compreender o comportamento dos clientes em relação à compra. Kotler e Keller (2012), por exemplo, observam que o comportamento de compra sofre influência, tanto de fatores endógenos quanto de fatores exógenos ao consumidor. No estudo, foram apontados como principais determinantes do comportamento: os fatores culturais e sociais (exógenos) e os fatores pessoais e psicológicos (endógenos). Porém, os autores destacam os fatores culturais como os que exercem influência maior e mais profunda no consumidor. Além disso, o artigo mostra a importância da ocupação e das circunstâncias econômicas no comportamento de compra, e a existência de produtos que atendem a necessidades específicas dos consumidores, conforme suas profissões e poder aquisitivo. Nesse sentido, são relevantes para o comportamento de compra fatores como: renda disponivel, as economias e os bens, débitos e atitudes em relação a gastar ou economizar (Kotler \& Keller, 2012).

Ao se aprofundar mais especificamente no processo de decisão de compra, procura-se, então, "atender uma necessidade do consumidor ainda não satisfeita pela empresa" (Cerqueira, Ferreira \& Costa, 2010, p. 5). No momento da compra, o consumidor despende esforços, que podem ser considerados de ordem física, financeira ou mental (Hanna \& Wagle, 1989, apud. Teixeira \& Hernandez, 2008).

A esse respeito, Kotler e Keller (2012) apresentam um modelo de cinco estágios, que traduzem o processo de decisão de compra do consumidor. Este processo tem como base os principais fatores psicológicos envolvidos no comportamento de compra, e incluem o reconhecimento do problema, ou seja, o reconhecimento da necessidade que se deseja suprir; a busca de informações a respeito do produto ou serviço que pode prover adequadamente a necessidade detectada; a avaliação das alternativas disponiveis; a decisão de compra; e, finalmente, o comportamento pós-compra.

Na fase de decisão de compra, o consumidor decide se irá comprar ou não e, Sheth et al. (2001) apontam que esta fase pode ser subdividida em outras três: a identificação da escolha, em que se chega a uma conclusão a partir das alternativas disponiveis; a intenção de compra, quando se verifica o orçamento e os parâmetros que tinham tornado determinado produto atrativo; e a realização da compra, na qual se verifica como e quando pagar.

A fase de decisão de compra é essencial para se estudar o comportamento do consumidor. Neste artigo, abordamos a etapa de decisão de compra em relação aos produtos orgânicos certificados.

\section{A DECISÃO DE COMPRA DE PRODUTOS ORGÂNICOS}

Com base no modelo apresentado, inúmeros estudos empíricos buscaram identificar as principais razões que levam os consumidores a optar por produtos orgânicos ao invés de produtos não orgânicos (Kriwy \& Mecking, 2011; Zanoli \& Naspetti, 2002; Aertenses, Verbeke, Mondelaers \& Huylenbroeck, 2009), e encontraram algumas semelhanças no comportamento de consumo dos chamados green products ao redor do mundo.

Nesse sentido, algumas pesquisas tiveram o objetivo de analisar o comportamento do consumidor de produtos orgânicos em diferentes países e regiões do mundo, como os Estados Unidos, a

OS, Organizações e Sustentabilidade, 8(1), p. 92-107, Londrina, PR, jan./jun. 2019. 
Europa, o Brasil e a China (Thøgersen, Barcellos, Perin \& Zhou, 2015; Zanoli \& Naspetti, 2002), buscando compreender suas características e peculiaridades locais. Pesquisas realizadas em países emergentes, como Brasil e China, evidenciam que as razões que levam brasileiros e chineses a consumir alimentos orgânicos são basicamente as mesmas encontradas na América do Norte e Europa; porém, as barreiras para o consumo de orgânicos em países em desenvolvimento são substancialmente maiores em relação à Europa e aos Estados Unidos, em termos de disponibilidade e altos preços, quando comparados com os alimentos não orgânicos.

Quanto ao consumo de produtos orgânicos, o 'nível educacional' é determinante para explicar o comportamento de compra desses produtos; quanto maior o número de anos de estudo, maiores as chances de os consumidores optarem por gastar com produtos orgânicos (Kriwy \& Mecking, 2011). Além disso, Zanoli e Naspetti (2002) e Mondelaers, Verbeke e Van-Huylenbroeck (2009), em estudo realizado na Europa, não encontraram nenhuma relação entre a variável estudada e a renda disponível. Por outro lado, Turra, Nielsen, Vian, Moreira e Ferrarezi (2015) afirmam que, no Brasil, renda é importante para explicar o consumo desses produtos, e quanto menor a renda, menor é a propensão ao consumo.

Ainda no contexto brasileiro, Turra et al. (2015) buscaram identificar o perfil do consumidor de alimentos orgânicos, investigando a propensão ao consumo a partir de variáveis como gênero, idade, nivel de educação e renda, em diferentes regiões brasileiras. Como resultado, de maneira geral, a maioria dos consumidores de orgânicos no Brasil são mulheres, com idade superior a 30 anos e renda mensal de 3 a 12 salários mínimos. Essas evidências corroboram os estudos mostrados anteriormente, principalmente quanto à idade e escolaridade.

Em consonância com o modelo de Kotler e Keller (2012), Kriwy e Mecking (2011) apontam a variável 'idade' como determinante do comportamento do consumidor e de sua atitude frente aos produtos orgânicos. De acordo com os autores, a relação entre idade e propensão ao consumo de orgânicos apresenta-se em forma de U invertido (Inverse U-shaped), ou seja, o consumo é crescente e mais acentuado até alcançar a faixa de 40 a 60 anos, sendo que, após essa faixa, verifica-se uma forte tendência de queda no consumo desses produtos.

Por outro lado, Aertenses et al. (2009) argumentam que o consumo de produtos orgânicos está diretamente ligado a valores individuais, sendo que a saúde, relacionada ao valor de segurança, é a que mais pesa na decisão de consumo. Já o sabor, sob a ótica do hedonismo, também tem influência, mas não é determinante no momento da compra. Os fatores motivacionais mais comumente mencionados são: cuidados com a saúde, melhor sabor, e respeito ao meio ambiente (Thøgersen et al., 2015).

Estudos como os de Silva, Camara e Dalmas (2005), Francisco et al. (2009) e Albuquerque et al. (2012) revelaram, contudo, que os principais motivadores da compra de produtos orgânicos podem ser hierarquizados do seguinte modo: o mais citado é a saúde e, em seguida vêm a confiança por um produto de melhor qualidade e mais sabor, e o cuidado com a preservação do meio ambiente, este último estreitamente relacionado à não utilização de agrotóxicos. Lima e Quevedo-Silva (2012), em seus estudos sobre a percepção do consumidor em relação aos orgânicos, além dos fatores saúde e sabor, afirmam que o produto orgânico também apresenta melhor aparência. Já Lombardi, Moori e Sato (2004) apontam a questão ambiental como o fator determinante para a decisão final do consumidor no momento da compra de produtos orgânicos.

Outro fator importante abordado na literatura, e que tem influência significativa na compra de produtos orgânicos, é a presença do selo de certificação, uma vez que este constitui uma importante ferramenta de comunicação entre produtores e consumidores, que garante a conformidade e credibilidade do processo produtivo (Francisco et al., 2009). Ainda nesse aspecto, Rodrigues et al. (2016) analisaram a relevância das certificações no consumo consciente, e 
observaram que a maioria dos entrevistados acredita que o selo de certificação confere maior credibilidade aos produtos. Hamza e Dalmarco (2012) também abordam os selos de certificação orgânicos, buscando entender o nivel de conhecimento dos consumidores, bem como sua influência nas decisões de consumo.

Apesar disso, alguns estudos mostraram que os consumidores não sabem reconhecer se um produto é certificado ou não, mesmo com a presença do selo na embalagem. Na pesquisa de Wander, Lacerda, Freitas, Didonet e Didonet (2007), dentre os consumidores de alimentos orgânicos considerados regulares, somente 5,7\% desses alegaram que conhecem alguma certificação, e apenas um respondente lembrou o nome de um selo orgânico utilizado em sua região. Já no trabalho de Kohlrausch, Campos e Selig (2004), sobre o conhecimento de selos orgânicos, apesar de grande parte da amostra afirmar que sabe o que é um rótulo orgânico, quando foram solicitados a citar algum nome conhecido, apenas 44\% responderam de forma correta.

É interessante destacar que nenhum desses estudos trata da questão dos selos de certificação como fator decisivo na compra, e nem consideram o selo como condição de seleção e compra de produtos orgânicos. Por isso, o conhecimento sobre os selos orgânicos e o processo de certificação desses produtos torna-se necessário dentro da academia.

\section{A CERTIFICAÇÃO DE PRODUTOS ORGÂNICOS}

Considera-se produto da agricultura orgânica, ou produto orgânico, seja ele in natura ou processado, aquele obtido em sistema orgânico de produção agropecuária ou oriundo de processo extrativista sustentável e não prejudicial ao ecossistema local. A mesma lei define o produtor como "toda pessoa, física ou jurídica, responsável pela geração de produto". Barbosa e Lages (2006, p. 31) destacam que:

A agricultura orgânica é um modelo agrícola no qual o consumidor adquire um produto classificado como orgânico, pois nele está buscando uma fonte de saúde e de qualidade de vida. Contudo, para esse produto ser classificado como orgânico, necessita que haja uma certificação formalmente estabelecida.

O processo de certificação de produtos orgânicos se originou do aumento da consciência da população urbana sobre os impactos que a agricultura tradicional exerce sobre os recursos naturais, além do crescimento dos movimentos ambientalistas. Com isso, aumentou a pressão para mudanças no paradigma de produção agropecuária, buscando-se sistemas de produção verdes, ecologicamente corretos e socialmente mais justos (Pinto \& Prada, 2000).

A certificação dos produtos orgânicos é uma exigência da Lei 10.831, de 23 de dezembro de 2003, que em seu Artigo 3 afirma que, para sua comercialização, os produtos orgânicos deverão ser certificados por organismo reconhecido oficialmente. Esta lei teve sua regulamentação apenas no ano de 2007, por meio do Decreto 6.323, emitido pelo Poder Executivo Federal. A partir da Lei e do Decreto, passamos a contar com uma série de medidas para a certificação dos produtos orgânicos, que é feita em duas etapas.

Primeiramente, parte-se do procedimento pelo qual uma certificadora, credenciada pelo Ministério da Agricultura, Pecuária e Abastecimento (Mapa) e credenciada pelo Instituto Nacional de Metrologia, Normalização e Qualidade Industrial (Inmetro), assegura, por escrito, que determinado produto obedece às normas e práticas da produção orgânica.

Além de atender aos regulamentos técnicos vigentes específicos para o produto que está sendo rotulado, os produtos inseridos no Sistema Brasileiro de Avaliação da Conformidade Orgânica deverão obedecer às determinações para rotulagem de produtos orgânicos, e conter o selo deste Sistema. Assim, a certificação consta de um selo afixado ou impresso no rótulo ou na embalagem do produto.

OS, Organizações e Sustentabilidade, 8(1), p. 92-107, Londrina, PR, jan./jun. 2019.

ISSN 2318-9223, http://www.uel.br/revistas/uel/index.php/ros/issue/view/1634/showToc 
A partir daí, para que um produto seja considerado orgânico e possa obter a certificação, ele deve conter as seguintes características: no caso de alimentos, não devem fazer mal à saúde (Linder, Uhl, Fliessbach, Trautner, Elger \& Weber, 2010); a agricultura deve ser sustentável, com a não utilização de adubos químicos; ter respeito pela saúde dos trabalhadores durante o processo de fabricação; ter produção em baixa escala; o sistema de produção deve ser local; devem imperar a preocupação e o respeito pelo meio ambiente; não podem conter sementes geneticamente modificadas e devem ser livres de agrotóxicos (Conner \& Christy, 2004). Além disso, os produtos orgânicos devem conter, pelo menos, 95\% de ingredientes orgânicos, segundo o Mapa; os produtos que possuem menos de $70 \%$ desses ingredientes não podem obter a certificação de orgânicos e, consequentemente, não apresentam em seu rótulo o selo nacional "Sisorg", o qual auxilia os consumidores no reconhecimento de produtos orgânicos comercializados em mercados e lojas especializadas (Mapa, 2018).

O Mapa aponta ainda três formas de o produtor orgânico fazer parte do Cadastro Nacional de Produtores Orgânicos, e todas são mecanismos de certificação: Certificação por Auditoria, dada por uma certificadora pública ou privada credenciada no Ministério; o Sistema Participativo de Garantia, que é um modelo de responsabilidade coletiva que pode ser formado por produtores, consumidores, técnicos e demais interessados, ou pelo Controle Social na Venda Direta, uma exceção na obrigatoriedade de certificação dos produtos orgânicos para a agricultura familiar. Esta última, desde que o produtor seja credenciado numa organização de controle social cadastrada em órgão fiscalizador oficial.

Com todo esse rigor para a certificação, é imprescindivel um controle no cumprimento de suas regras, por meio da fiscalização dos produtos orgânicos, que é feita pelo Mapa e pelos próprios certificadores, que alimentam o Cadastro Nacional de Produtores Orgânicos. O Decreto 6.323/07 indica os vários locais onde deve ser exercida a fiscalização, abrangendo desde o manuseio até as etapas finais de venda, e são descritos detalhadamente em seu artigo 58, transcrito a seguir:

\begin{abstract}
A inspeção e a fiscalização de que trata este Decreto serão realizadas em unidades de produção, estabelecimentos comerciais e industriais, cooperativas, órgãos públicos, portos, aeroportos, postos de fronteira, veículos e meios de transporte, e quaisquer outros ambientes onde se verifique a produção, beneficiamento, manipulação, industrialização, embalagem, acondicionamento, transporte, distribuição, comércio, armazenamento, importação e exportação de produtos orgânicos.
\end{abstract}

O Decreto também prevê que a fiscalização seja exercida "por servidores públicos de nível superior, capacitados e autorizados pelo órgão competente, com formação profissional compativel com a atividade desempenhada". São previstas multas que podem chegar a 1 milhão de reais, sem prejuizo da responsabilidade civil e penal cabível, ou seja, o pagamento da multa não exime o infrator de um processo criminal ou de indenizações na esfera civil, pagas a quem ele imponha prejuízo. Assim, o produtor que adulterar ou falsificar produto, em descumprimento à legislação, pode ser advertido, autuado ou ter seus produtos apreendidos, chegando até a perder seu cadastro de agricultor.

A produção de orgânicos tem um apelo voltado para a vida saudável, com produtos sem uso de transgênicos ou agrotóxicos. Além do apelo à saúde do indivíduo, também compreende o apelo à preservação da natureza, com uma produção agrícola mais natural, que não utiliza fertilizantes sintéticos. A certificação identifica e controla a produção e as demais etapas do processo, de forma a dar credibilidade ao produtor, o qual, a partir da certificação, adquire outras possibilidades de atingir mercados consumidores de seus produtos, pela exportação. 


\section{PROCEDIMENTOS METODOLÓGICOS}

Quanto à abordagem, esta pesquisa caracteriza-se como quantitativa, segundo a descrição de Malhotra (2001, p.155): "a pesquisa qualitativa proporciona uma melhor visão e compreensão do contexto do problema, enquanto a pesquisa quantitativa procura quantificar os dados e aplica alguma forma de análise estatística".

Em relação aos procedimentos de coleta de dados, realizamos a pesquisa por meio de survey. Sobre esse tipo de procedimento, Fonseca (2002) observa que o questionário é o instrumento de pesquisa selecionado para obter informações acerca de determinadas opiniões ou características de grupos específicos de pessoas.

Para atender aos objetivos de pesquisa, primeiramente foi criado um questionário com base na literatura sobre o tema de pesquisa. Para Cervo e Bervian (2002, p. 48), o questionário "refere-se a um meio de obter respostas às questões por uma fórmula que o próprio informante preenche". Sendo o questionário composto de perguntas fechadas, distribuídas em cinco blocos: bloco filtro, composto por duas questões, sendo que na primeira era perguntado se os respondentes já haviam consumido produtos orgânicos, e na segunda, se estes consumidores sabiam o que era um selo de certificação; bloco 1, apresentando questões sobre o selo como fator de decisão; bloco 2, sobre o conhecimento dos selos de certificação orgânica; bloco 3, que abordava os motivos da decisão de compra de produtos orgânicos certificados; e bloco 4, com informações sobre o respondente. Sobre as vantagens desse tipo de instrumento, Lakatos e Marconi (1996) destacam a economia, a garantia de anonimato dos respondentes, a possibilidade de alcance de maior quantidade de pessoas, e a padronização das perguntas, o que pode influenciar a uniformização das respostas.

Após a criação do questionário, em um segundo momento foi realizado um pré-teste com 12 consumidores de produtos orgânicos. O objetivo da aplicação de um questionário-teste (Malhotra, 2006) é a possibilidade de levantamento de problemas potenciais e a sua remoção. Desse modo, após a identificação e resolução de problemas como correções gramaticais e questões com sentido dúbio, foi criado o formulário na plataforma Google Docs para envio online do questionário.

A técnica não probabilística "bola de neve" foi utilizada na da pesquisa. Os pesquisadores indicaram alguns possiveis respondentes, que por sua vez indicaram outros, e assim, de forma sucessiva, até que fosse alcançado um número suficiente de respostas para atender aos objetivos da pesquisa (Baldin \& Munhoz, 2011). A amostra inicial era composta de 212 respostas; no entanto, após os filtros, a amostra foi reduzida conforme descrito a seguir: 18 respostas estavam incompletas; 194 respostas passaram pelo primeiro filtro (35 respostas "descartadas", pois os respondentes nunca compraram produtos orgânicos, restando 159 respondentes); 159 respostas passaram pelo segundo filtro, completando todo o questionário (39 respostas "descartadas", pois os respondentes não sabiam o que era um selo de certificação). Assim, a amostra final conteve 120 respostas, as quais foram analisadas com o suporte do software Stata-SE versão 12 (2011) e da planilha Excel.

É necessário destacar que o primeiro tópico da análise de resultados possui a descrição da amostra inicial (194 respondentes). Optamos por apresentar esses resultados, por estarem de acordo com as referências teóricas, apesar de nossa amostra final ser composta por 120 clientes, os quais consomem ou já consumiram produtos orgânicos e sabem o que é um selo de certificação (questões-filtro do questionário).

OS, Organizações e Sustentabilidade, 8(1), p. 92-107, Londrina, PR, jan./jun. 2019. 


\section{ANÁLISE E DISCUSSÃO DOS RESULTADOS}

\section{ANÁLISE DE RESULTADOS DA AMOSTRA INICIAL}

A frequência observada do consumo de produtos orgânicos mostra que a maioria dos consumidores não possui o hábito de comprar este tipo de produto. A Tabela 1 evidencia que grande parte dos respondentes (48,45\%) afirma consumir produtos orgânicos apenas às vezes, e é seguida por aqueles que afirmam que frequentemente consomem orgânicos (19,59\%), nunca consomem (18,04\%), consumiram uma única vez (9,79\%) e só consomem produtos orgânicos (3,61\%). Além disso, um dos respondentes apontou a influência do preço no momento da compra, questão mencionada como determinante por Turra et al., (2015).

Em relação aos respondentes que consomem produtos orgânicos ou já consumiram pelo menos uma vez, é possível observar que grande parte deles (75,47\%) afirma saber o que é um selo de certificação. Apesar disso, ainda existem consumidores que não possuem conhecimentos básicos a respeito das funções e significados dos selos de certificação orgânica, conforme exposto por Kohlrausch et al., (2004) e Hamza e Dalmarco (2012).

TABELA 1 - FREQUÊNCIA DE CONSUMO

\begin{tabular}{l|l|l|l}
\hline & \multicolumn{1}{|c|}{$\begin{array}{c}\text { Frequência } \\
\text { Absoluta }\end{array}$} & \multicolumn{1}{|c|}{$\begin{array}{c}\text { Frequência Relativa } \\
(\%)\end{array}$} & \multicolumn{1}{|c}{$\begin{array}{c}\text { Frequência Acumulada } \\
\text { (\%) }\end{array}$} \\
\hline $\begin{array}{l}\text { Apenas quando o preço está } \\
\text { próximo }\end{array}$ & 1 & 0,52 & 0,52 \\
\hline Comprei uma única vez & 19 & 9,79 & 10,31 \\
\hline Frequentemente & 38 & 19,59 & 29,90 \\
\hline Nunca compro produtos orgânicos & 35 & 18,04 & 47,94 \\
\hline Só compro produtos orgânicos & 7 & 3,61 & 51,55 \\
\hline Às vezes & 94 & 48,45 & 100,00 \\
\hline Total & 194 & 100,00 & \\
\hline
\end{tabular}

Fonte: Elaborado com dados da pesquisa.

\section{ANÁLISE DE RESULTADOS DA AMOSTRA FINAL}

\section{ESTATISTICAS DESCRITIVAS}

O consumo de produtos orgânicos é feito principalmente por mulheres (64,2\%), o que está de acordo com Turra et al. (2015). Esse resultado pode ser explicado pelo fato de, geralmente, as mulheres serem responsáveis por fazer as compras para a casa. Em relação à faixa etária, o consumo de produtos orgânicos é maior na faixa entre 41 e 60 anos (35,8\%), conforme mostrado por Kriwy e Mecking (2011). Porém, ao contrário do exposto pelos autores, que encontraram uma relação "U invertida" entre idade e consumo de orgânicos, nosso estudo sugere que o consumo de produtos orgânicos também é significativo (20\%) e tem crescido entre consumidores de 25 a 30 anos.

Os resultados também comprovam a relação positiva entre consumo de orgânicos e grau de instrução e escolaridade, já apresentada na literatura (Kriwy \& Mecking, 2011; Hamza \& Dalmarco, 2012). Nosso estudo mostra que $84,2 \%$ dos respondentes possuem nivel superior, sendo que $47,5 \%$ com pós-graduação e 36,7\% com graduação. Do mesmo modo, a renda total mensal familiar também possui relação positiva com o consumo de orgânicos, sendo que 35\% dos respondentes que quiseram declarar possuem renda mensal acima de oito salários mínimos, contrariando 0 estudo de Zanoli \& Naspetti (2002), mas corroborando o trabalho de Turra et al. (2015). Essa diferença pode ser explicada pelo fato de as pesquisas terem ocorrido em países desenvolvidos e

OS, Organizações e Sustentabilidade, 8(1), p. 92-107, Londrina, PR, jan./jun. 2020.

ISSN 2318-9223, http://www.uel.br/revistas/uel/index.php/ros/issue/view/1634/showToc 
emergentes, respectivamente, onde o poder aquisitivo dos consumidores é consideravelmente distinto.

As frutas, legumes e verduras são o tipo de produto orgânico mais consumido entre os respondentes $(90,8 \%)$, seguidos por sucos $(43,3 \%)$ e embalados $(40,8 \%)$ e cosméticos $(15,8 \%)$. Esses produtos são adquiridos em supermercados (67,5\%), feiras $(48,3 \%)$ e lojas especializadas $(38,3 \%)$ e são, em sua maioria, consumidos por pessoas que prezam um estilo de vida mais saudável.

\section{RECONHECIMENTO DO SELO DE CERTIFICAÇÃO}

Com o objetivo de testar o conhecimento dos consumidores de produtos orgânicos a respeito dos diversos selos de certificação, foram apresentados no questionário nove selos sustentáveis, dentre os quais apenas cinco se referiam à adequação da produção de orgânicos às determinações do Mapa. Foi solicitado que os respondentes apontassem apenas os selos que, segundo eles, relacionavam-se aos produtos orgânicos. A Tabela 2 mostra o quanto cada grupo de consumidores, divididos pela frequência de consumo, foi capaz de identificar os selos. A partir da análise ANOVA, tem-se que o valor-p $(0,0314)$ menor que $5 \%$ indica que há diferença significativa entre as médias de acerto nos diferentes grupos.

TABELA 2 - ANÁLISE DE VARIÂNCIA (ANOVA) ENTRE FREQUÊNCIA DE COMPRAS DE PRODUTOS ORGÂNICOS E CONHECIMENTO SOBRE OS SELOS DE CERTIFICAÇÃO

\begin{tabular}{l|l|l|l|l|l}
\hline & SS & df & MS & F & Prob $>$ F \\
\hline Entre os grupos & 13,931 & 4 & 3,4828 & 2,7500 & 0,0314 \\
\hline Dentro dos grupos & 145,536 & 115 & 1,2655 & & \\
\hline Total & 159,467 & 119 & 1,3401 & & \\
\hline Teste de Esfericidade de Bartlett & $\chi^{2}(3)=$ & 5 & & Prob $>\chi^{2}=$ & 0,162 \\
\hline
\end{tabular}

Fonte: Elaborado com dados da pesquisa.

Para analisar as diferenças de médias entre os grupos, bem como identificar os grupos mais ou menos capazes de reconhecer os diferentes selos, foi realizado o teste de comparação de médias de Bonferroni (Tabela 3). A única resposta relativa ao preço foi retirada pelo software, por não apresentar significativa representatividade na análise. O teste apresentou um valor-p $(0,082)$ estatisticamente significativo entre os grupos 1 e 2 (compraram apenas uma vez e compram frequentemente). Os respondentes que possuem o hábito de consumir produtos orgânicos mais frequentemente são, em média, mais capacitados no reconhecimento dos selos de certificação (Hamza \& Dalmarco, 2012), além de apresentarem maior familiaridade com eles. Por outro lado, os outros grupos não apresentaram médias de acerto diferentes, ou seja, estatisticamente, são igualmente capazes de reconhecer selos de certificação orgânica.

TABELA 3 - TESTE DE MÚLTIPLAS COMPARAÇÕES ENTRE MÉDIAS DE BONFERRONI

\begin{tabular}{|c|c|c|c|c|c|c|}
\hline & Média & Desvio-Padrão & 1 & 2 & 3 & 4 \\
\hline Comprei uma única vez (1) & 0,90 & 0,74 & - & & & \\
\hline Frequentemente (2) & 2,00 & 1,34 & $0,082 *$ & - & & \\
\hline Só compro produtos orgânicos (3) & 2,20 & 1,30 & $0,370 \mathrm{~ns}$ & 1,000 ns & - & \\
\hline Às vezes (4) & 1,42 & 1,05 & 1,000 ns & $0,187^{\text {ns }}$ & 1,000 ns & - \\
\hline Total & 1,57 & 1,16 & & & & \\
\hline
\end{tabular}

OS, Organizações e Sustentabilidade, 8(1), p. 92-107, Londrina, PR, jan./jun. 2019.

ISSN 2318-9223, http://www.uel.br/revistas/uel/index.php/ros/issue/view/1634/showToc 


\section{INFLUÊNCIA DO SELO DE CERTIFICAÇÃO NA COMPRA DE PRODUTOS ORGÂNICOS}

A importância dada ao selo orgânico pelo consumidor pode ser mensurada através da percepção de uma série de benefícios garantidos pela certificação. Quanto menos o consumidor reconhece esses benefícios, menor é a influência do selo de certificação sobre a sua decisão de compra. Para avaliar o quanto o selo é decisivo no momento da compra, bem como a importância dos benefícios associados, propõe-se o seguinte modelo:

Importância $=\beta \_0+\beta \_1$ Pres $+\beta \_2$ Irrelevância $+\beta \_3$ Sustentabilidade $+\beta \_4$ Preço_S $+\beta \_5$ Preço_l+ $\beta$ _6 Preço_In+ $\varepsilon$

A variável 'Presença' indica a importância que o consumidor atribui à visualização do selo de certificação na embalagem ou no produto orgânico a ser adquirido. A variável 'Irrelevância' reflete a decisão do consumidor de comprar o produto orgânico, mesmo sem ser capaz de encontrar e visualizar o selo. A 'Sustentabilidade' surge como uma alternativa ao selo, ou seja, em que medida o consumidor procura por indicações de fabricação sustentável dos produtos, quando estes não possuem um selo de certificação. Já as variáveis relacionadas ao preço, buscam refletir o valor que o consumidor atribui ao selo de certificação, bem como a todos os benefícios e garantias proporcionados pelo mesmo. Assim, foram avaliadas as situações em que o preço é superior (Preço_S), igual (Preço_I) e inferior (Preço_In). Os resultados da regressão são apresentados na Tabela 4. Todos os critérios de qualidade de ajuste do modelo foram atendidos (colinearidade, homocedasticidade, omissão de variável e normalidade do termo de erro).

TABELA 4 - IMPORTÂNCIA ATRIBUÍDA AO SELO DE CERTIFICAÇÃO ORGÂNICO PELOS CONSUMIDORES

\begin{tabular}{|c|c|c|c|c|c|c|}
\hline \multirow{2}{*}{$\begin{array}{l}\text { Import. } \\
\text { PRES (Dec1) }\end{array}$} & \multirow{2}{*}{$\begin{array}{l}\text { Coeficientes } \\
0,710\end{array}$} & \multirow{2}{*}{$\begin{array}{l}\text { Erro Padrão } \\
0,282\end{array}$} & \multirow{2}{*}{$\frac{t}{2,520}$} & \multirow{2}{*}{$\frac{P>|t|}{0,013}$} & \multicolumn{2}{|c|}{ Intervalo de Confiança } \\
\hline & & & & & 0,151 & 1,270 \\
\hline IRREL (Dec2) & $-0,418$ & 0,128 & $-3,270$ & 0,001 & $-0,672$ & $-0,165$ \\
\hline SUSTENT (Dec3) & $-0,024$ & 0,153 & $-0,160$ & 0,875 & $-0,328$ & 0,279 \\
\hline PREÇO_S (Dec4) & 0,535 & 0,264 & 2,020 & 0,046 & 0,011 & 1,058 \\
\hline PREÇO_I (Dec5) & 0,025 & 0,160 & 0,150 & 0,878 & $-0,293$ & 0,342 \\
\hline PREÇO_In (Dec6) & 0,001 & 0,129 & 0,010 & 0,995 & $-0,254$ & 0,255 \\
\hline _Cons & 4,050 & 1,239 & 3,270 & 0,001 & 1,596 & 6,504 \\
\hline
\end{tabular}

0 poder explicativo do modelo proposto é de 38\%. A variável Dec1, que indica a visualização do selo, está positivamente relacionada com a importância dada ao mesmo. Assim, é possivel afirmar que os consumidores que buscam a presença do selo, como garantia de produção orgânica, são os que dão maior importância ao seu significado e aos benefícios que este representa. Por outro lado, a variável Dec2, que reflete a indiferença do consumidor em relação ao selo de certificação, está negativamente relacionada à importância atribuída à certificação, como esperado. Já Dec3, Dec5 e Dec6 não se mostraram significativas no modelo ( $t=-0,16 ; 0,150$ e 1,010, respectivamente), ou seja, não são capazes de explicar a importância que o consumidor atribui ao selo de certificação. Essa falta de relação indica que os consumidores que dão maior importância ao selo de certificação não buscam, como alternativas, indicações de fabricação sustentável. Para estes, apenas apontar que 0 produto é integral, natural, light ou que foi produzido de maneira sustentável, não substitui a presença do selo de certificação. A variável Dec5 tem relação positiva e significativa com a importância dada ao selo de certificação, ou seja, os consumidores que dão importância ao selo não se incomodam em pagar um pouco mais por um produto orgânico certificado (Hamza \& Dalmarco, 2012).

OS, Organizações e Sustentabilidade, 8(1), p. 92-107, Londrina, PR, jan./jun. 2020.

ISSN 2318-9223, http://www.uel.br/revistas/uel/index.php/ros/issue/view/1634/showToc 


\section{MOTIVADORES DE COMPRA DE PRODUTOS ORGÂNICOS CERTIFICADOS}

A literatura aponta inúmeras razões para o consumidor optar pela compra de um produto orgânico. Dentre elas, as mais recorrentes são: credibilidade (Rodrigues et al., 2016), saúde (Aertenses et al., 2009), respeito ao meio ambiente (Thøgersen et al., 2015; Lombardi et. al.,2004), qualidade (Albuquerque et al., 2012) e aparência (Lima \& Quevedo-Silva, 2012). O questionário solicitava ao respondente que apontasse, dentre esses, os principais motivos que o levavam a comprar produtos orgânicos, sendo possivel assinalar mais de uma resposta.

Com o objetivo de compreender as razões apontadas pelo consumidor, bem como identificar as que mais influenciam sua decisão de compra, realizou-se o teste de diferença de médias (t-Student), mostrado na Tabela 5. A análise inicial das médias indica que a credibilidade $(4,33)$ é o motivador mais importante para a compra de produtos orgânicos certificados, seguido pela qualidade (4), respeito ao meio ambiente $(3,84)$, saúde $(3,78)$ e aparência $(3,23)$ dos produtos orgânicos garantidos pela certificação. As diagonais apresentam os valores relativos às interações entre os motivadores, mostrando se há diferença entre médias, de dois em dois. Apenas as médias dos motivadores relacionados ao respeito ao meio ambiente e à saúde não são diferentes estatisticamente (valor $\mathrm{p}=0,06$ ), ou seja, não é possivel determinar qual dos dois tem maior influência na decisão de compra. A ordem de importância em que os motivadores se apresentam nesta pesquisa difere de pesquisas anteriores, que mostram a saúde como principal razão para a compra de produtos orgânicos (Silva et al., 2005; Francisco et al., 2009; Albuquerque et al., 2012).

TABELA 5 - DIFERENCA ENTRE AS MÉDIAS DOS MOTIVADORES DE COMPRA DE PRODUTOS COM SELO ORGÂNICO

\begin{tabular}{|c|c|c|c|c|c|}
\hline & Credibilidade & Saúde & $\begin{array}{l}\text { Respeito ao } \\
\text { Meio Ambiente }\end{array}$ & Qualidade & Aparência \\
\hline Credibilidade & 4,33 & & & & \\
\hline Saúde & $0,55^{* * *}$ & 3,78 & & & \\
\hline $\begin{array}{l}\text { Respeito ao Meio } \\
\text { Ambiente }\end{array}$ & $0,49 * * *$ & 0,06 ns & 3,84 & & \\
\hline Qualidade & $0,33^{* * *}$ & $0,22^{* * *}$ & $0,16^{*}$ & 4,00 & \\
\hline Aparência & $1,11^{* * *}$ & $0,56^{* * *}$ & $0,62^{* * *}$ & $0,78^{* * *}$ & 3,23 \\
\hline
\end{tabular}

Adicionalmente, com o intuito de entender a relação entre os cinco motivadores apresentados, realizou-se o teste de correlação de Spearman, cujos resultados são apresentados na Tabela 6.

TABELA 6 - CORRELAÇÃO ENTRE OS MOTIVADORES DE COMPRA DE PRODUTOS COM SELO ORGÂNICO

\begin{tabular}{|c|c|c|c|c|c|}
\hline & Credibilidade & Saúde & $\begin{array}{l}\text { Respeito ao Meio } \\
\text { Ambiente }\end{array}$ & Qualidade & Aparência \\
\hline Credibilidade & 1 & & & & \\
\hline Saúde & $0,45^{* * *}$ & 1 & & & \\
\hline $\begin{array}{l}\text { Respeito ao Meio } \\
\text { Ambiente }\end{array}$ & $0,43^{* * *}$ & $0,69 * * *$ & 1 & & \\
\hline Qualidade & $0,57^{* * *}$ & $0,66^{* * *}$ & $0,55^{* * *}$ & 1 & \\
\hline Aparência & $0,06 \mathrm{~ns}$ & $0,20 * *$ & $0,29 * * *$ & 0,10 ns & 1 \\
\hline
\end{tabular}

O motivador relacionado à saúde é o que apresenta os maiores resultados quando correlacionado aos demais motivadores. Em 69\% dos casos, os respondentes acreditam, concomitantemente, que a saúde e o respeito ao meio ambiente são fatores decisivos na compra de produtos orgânicos. Igualmente, a saúde relaciona-se à qualidade, em $66 \%$ dos casos. 0 motivador relacionado à

OS, Organizações e Sustentabilidade, 8(1), p. 92-107, Londrina, PR, jan./jun. 2019.

ISSN 2318-9223, http://www.uel.br/revistas/uel/index.php/ros/issue/view/1634/showToc 
aparência não apresentou resultados significativos nas duas análises, contrariando o exposto por Lima e Quevedo-Silva (2012).

\section{CONCLUSÕES}

A obrigatoriedade de certificação de produtos orgânicos é uma garantia de controle e fiscalização para que o produto esteja livre de agrotóxico e adubos químicos, qualidades difíceis de serem identificadas por uma pessoa comum. Assim, coube ao Ministério da Agricultura, Pecuária e Abastecimento - Mapa, a incumbência de credenciar e fiscalizar Certificadoras capazes de aferir o cumprimento das regras trazidas pela legislação, a partir da Lei 10.831, de 23 de dezembro de 2003 e do Decreto $n^{0}$ 6.323, que regulamentou a matéria em 2007, acompanhando a normatização internacional, que também estabelece regras para a exportação desses produtos. Nesta perspectiva, a certificação traz segurança para o consumidor.

Os resultados desta pesquisa apontaram que a maioria dos consumidores de orgânicos no Brasil são mulheres, com idade superior a 30 anos e com renda mensal de três a 12 salários mínimos, confirmando estudos anteriores.

Em relação à relevância das certificações, a maioria dos entrevistados acredita que o selo de certificação confere maior credibilidade aos produtos.

A maioria dos consumidores apresenta baixa frequência de compras. A Tabela 1 evidencia que grande parte dos respondentes (48,45\%) afirma consumir produtos orgânicos apenas às vezes.

Em relação aos respondentes que consomem produtos orgânicos ou já consumiram pelo menos uma vez, é possivel observar que 75,47\% afirmam saber o que é um selo de certificação; apesar disso, alguns estudos comprovaram que os consumidores não sabem reconhecer se um produto é certificado ou não, mesmo com a presença do selo na embalagem.

Os resultados também comprovam a relação positiva entre consumo de orgânicos e grau de instrução e escolaridade, já apresentado na literatura (Kriwy \& Mecking, 2011; Hamza \& Dalmarco 2012).

Este estudo mostra que $84,2 \%$ dos respondentes possuem nivel superior, sendo que 47,5\% são pós-graduados e $36,7 \%$ são graduados. Igualmente, a renda total mensal familiar também possui relação positiva com o consumo de orgânicos, sendo que 35\% dos respondentes que quiseram declarar possuem renda mensal acima de oito salários mínimos, contrariando o estudo de Zanoli e Naspetti (2002), mas confirmando o de Turra et al. (2015). Essa diferença pode ser explicada pelo fato de as pesquisas terem ocorrido em países desenvolvidos e emergentes, respectivamente, onde o poder aquisitivo dos consumidores é bastante distinto.

As frutas, legumes e verduras são o tipo de produto orgânico mais consumido entre os respondentes $(90,8 \%)$, seguidos por sucos $(43,3 \%)$ e embalados $(40,8 \%)$ e cosméticos $(15,8 \%)$. Esses produtos são adquiridos em supermercados (67,5\%), feiras (48,3\%) e lojas especializadas $(38,3 \%)$ e são, em geral, consumidos por pessoas que prezam um estilo de vida mais saudável; 0 motivador relacionado à saúde é o que apresenta os maiores resultados, quando correlacionado aos demais motivadores.

Sobre o primeiro objetivo deste estudo, o reconhecimento dos selos de certificação orgânica pelos consumidores, foi identificado que aqueles que consumiram apenas uma vez e os que consomem produtos orgânicos frequentemente são igualmente capazes de reconhecer tais selos.

lá em relação à influência do selo de certificação na compra de produtos orgânicos, o segundo objetivo da pesquisa, verificou-se que os consumidores que procuram o selo na embalagem dos produtos são os que mais acreditam nos seus benefícios. Além disso, os consumidores não

0S, Organizações e Sustentabilidade, 8(1), p. 92-107, Londrina, PR, jan./jun. 2020.

ISSN 2318-9223, http://www.uel.br/revistas/uel/index.php/ros/issue/view/1634/showToc 
acreditam que o fato de o produto possuir indicações de fabricação sustentável pode substituir a presença do selo de certificação, no caso dos produtos orgânicos.

Acerca do terceiro objetivo, os motivadores de compra de orgânicos, em 69\% dos casos os respondentes acreditam, concomitantemente, que a saúde e o respeito ao meio ambiente são fatores decisivos na compra de tais produtos. Da mesma maneira, a saúde relaciona-se à qualidade em $66 \%$ dos casos. 0 motivador relacionado à aparência não apresentou resultados significativos nas duas análises, contrariando o exposto por Lima e Quevedo-Silva (2012).

É importante destacar que nenhum desses estudos que fazem parte da literatura estudada, tratam da questão dos selos de certificação como fator decisivo na compra, e nem abordam o selo como condição de seleção e compra de produtos orgânicos. Por isso, o conhecimento sobre os selos orgânicos e o processo de certificação desses produtos se faz necessário dentro da academia, e, por sua relevância, sugere-se estimular novos estudos. Nesse sentido, recomenda-se uma adaptação do instrumento de coleta de dados, para englobar os consumidores que não sabem identificar selos de certificação, mas que consomem produtos orgânicos, buscando compreender melhor como eles entendem o processo de certificação de orgânicos.

Sobre as limitações desta pesquisa, ressalta-se a utilização da amostra por conveniência, o que não permite realizar afirmações gerais, com o devido rigor estatístico, a respeito da população.

\section{REFERÊNCIAS}

Aertesens, J., Verbeke, W., Mondelaers, K., \& Van Huylenbroeck, G. (2009) Personal determinants of organic food consumption: A review. British Food Journal, 111(10), 1149-1167.

Albuquerque, E. P., Junior, Silva, J. C. L., Filho, Costa, J. C., \& Santos, S. M. (2013). Aspectos relativos à saúde e ao meio ambiente ligados ao consumo de alimentos orgânicos. ReA UFSM-Revista de Administração da UFSM, 6, 927-943.

Baldin, N., \& Munhoz, E. M. B. (2011). Educação ambiental comunitária: uma experiência com a técnica de pesquisa snowball (bola de neve). REMEA-Revista Eletrônica do Mestrado em Educação Ambiental, 27. DOI: https://doi.org/10.14295/remea.v27i0.3193

Barbosa, L. C. B. G, \& Lages, A. M. G. (2006). Crença e certificação de produtos orgânicos: o exemplo da feira de Maceió. In Anais do $3^{\circ}$ Encontro da Associação Nacional de Pós-Graduação e Pesquisa em Ambiente e Sociedade (ANPPAS), Brasília, DF.

Blackwell, R. D., Miniard, P. W., \& Engel, J. F. (2005). Comportamento do consumidor (Tradução da ga ed. americana). São Paulo: Cengage Learning.

Cerqueira, L. S., Ferreira, H. M. P., \& Costa F. M. (2010). Comportamento do consumidor: um estudo da percepção do consumidor no segmento atacadista em um município baiano. In Anais do XIII SemeAd -Seminários em Administração. FEA/USP, São Paulo, SP.

Cervo, A. L., \& Bervian, P. A. (2002). Metodologia científica (5a ed.). São Paulo: Prentice Hall.

Conner, D., \& Christy, R. (2004). The organic label: How to reconcile its meaning with consumer preferences. Journal of Food Distribution Research, 35(1), 40-43.

Decreto $n^{0}$ 6.323, de 27 de dezembro de 2007 (2007). Regulamenta a Lei no 10.831, de 23 de dezembro de 2003, que dispõe sobre a agricultura orgânica, e dá outras providências. Recuperado em 8 de abril, 2018, de http://www.planalto.gov.br/CCIVil_03/_Ato20072010/2007/Decreto/D6323.htm.

Fonseca, J. J. S. (2002). Metodologia da pesquisa científica. Fortaleza: UEC.

OS, Organizações e Sustentabilidade, 8(1), p. 92-107, Londrina, PR, jan./jun. 2019.

ISSN 2318-9223, http://www.uel.br/revistas/uel/index.php/ros/issue/view/1634/showToc 
Francisco, E. S., Moura, F. A., Zanon, R. S., \& Marinho, B. de L. (2009). Comportamento do consumidor na compra de produtos orgânicos. In Anais do XII SemeAd - Seminários em Administração. FEA/USP, São Paulo, SP.

Hamza, K. M., \& Dalmarco, D. A. S. (2012). As certificações sustentáveis e sua relevância para 0 consumo consciente e os negócios. Reunir-Revista de Administração, Contabilidade e Sustentabilidade, 2(2), 1-20. http://dx.doi.org/10.18696/reunir.v2i2.67.

Kohlrausch, A. K., Campos, L. M. S., \& Selig, P. M. (2004) O comportamento do consumidor de produtos orgânicos em Florianópolis: uma abordagem estratégica. Revista Alcance, 11(1),157-177.

Kotler, P. (1998). Administração de Marketing: Análise, Planejamento, Implementação e Controle (5ªd.) São Paulo: Atlas.

Kotler, P., \& Keller, K. L. (2012). Administração de Marketing (14a ed.). São Paulo: Pearson Education.

Kriwy, P., \& Mecking, R. A. (2011). Health and environmental consciousness, costs of behavior and the purchase of organic food. International Journal of Consumer Behavior, 36(1), 30-37.

Lakatos, E. M., \& Marconi, M. A. (1996). Técnicas de Pesquisa (3a ed. rev. e ampl.) São Paulo: Atlas.

Lei $n^{0}$ 10.831, de 23 de dezembro de 2003 (2003). Dispõe sobre a agricultura orgânica e dá outras providências. Recuperado em 9 de abril, 2018, de http://www.planalto.gov.br/ccivil_03/leis/2003//10.831.htm.

Lima, D. O, Filho, \& Quevedo-Silva, F. (2012). Percepção do consumidor sobre produtos orgânicos. Revista Brasileira de Marketing, 11(1), 24-47.

Linder, N. S., Uhl, G., Fliessbach, K., Trautner, P., Elger, C. E., \& Weber, B. (2010) Organic labelling influences food valuation and choice. Neuroimage, 53, 215-220.

Lombardi, M. S., Moori, R. G., \& Sato, G. S. (2004). Um estudo exploratório dos fatores relevantes na decisão de compra de produtos orgânicos. Revista de Administração Mackenzie, 5(1), 14-34.

Malhotra, N. (2001). Pesquisa de Marketing (3a ed.). Porto Alegre: Bookman.

Malhotra, N. (2006). Pesquisa de Marketing: uma orientação aplicada (4a ed.). Porto Alegre: Bookman.

Ministério da Agricultura, Pecuária e Abastecimento. Orgânicos. Recuperado em 7 de abril, 2018, de http://www.agricultura.gov.br/assuntos/sustentabilidade/organicos/o-que-sao-organicos

Mondelaers K., Verbeke, W., \& Van Huylenbroeck, G. (2009). Importance of health and environment as quality traits in the buying decision of organic products. British Food Journal, 111(10), 1120-1139.

Pinto, L. F. G., \& Prada, L. de S. (2000). Fundamentos da certificação socioambiental. In Ferraz, J. M. G., Prada, L. de S., \& Paixão, M. (Orgs.) Certificação socioambiental do setor sucroalcooleiro (pp. 15-31). São Paulo: Embrapa Meio Ambiente.

Rodrigues, D. B., Dalmarco, D. A. S., Aoqui, C., \& Marinho, B. L. (2016). The meaning of the organic certification label for the consumer: a cluster analysis. Revista de Gestão, 23(4), 316-325.

Sheth, J. N., Mittal, B., \& Newman, B. I. (2001). Comportamento do cliente: indo além do comportamento do consumidor. São Paulo: Atlas.

Silva, D. M., Camara, M. R. G., \& Dalmas, J. C. (2005). Produtos orgânicos: Barreiras para a disseminação do consumo de produtos orgânicos no varejo de supermercados em Londrina-PR. Semina: Ciências Sociais e Humanas, 26, 95-104. DOl: http://dx.doi.org/10.5433/16790383.2005v26n1p95. 
Solomon, M. R. (2002). Comportamento do consumidor (5a ed.). São Paulo: Artmed.

Solomon, M. R. (2011) O comportamento do consumidor: comprando, possuindo e sendo (9a ed.). Porto Alegre: Bookman.

StataCorp. 2011. Stata Statistical Software: Release 12. College Station, TX: StataCorp LP.

Teixeira, J. M., \& Hernandez, J. M. C. (2008). O papel moderador do nível de estimulação ideal nas relações entre os valores de compra e esforço e variáveis de resultado do varejo. In $32^{\circ}$ Encontro da Associação Nacional de Pós-Graduação e Pesquisa em Administração-EnANPAD. Rio de Janeiro, RJ.

Thøgersen J., Barcellos, M. D., Perin, M. G., \& Zhou, Y. (2015). Consumer buying motives and attitudes towards organic food in two emerging markets: China and Brazil. International Marketing Review, 32(3/4), 389-413.

Trevizan, S. D. P., \& Casemiro, A. D. (2009). Consumidores de produtos orgânicos em Vitória da Conquista, BA. In Proceedings of the 2nd International Workshop Advances in Cleaner Production, São Paulo, SP.

Turra, C., Nielsen, F. A. G, Vian, C. E. F, Moreira, C. F., \& Ferrarezi, C. (2015). The Brazilian consumer's profile and perceptions of organic foods: a review. Global Advanced Research Journal of Agricultural Science, 4(11), 775-783.

Wander, A. E., Lacerda, A. C. V., Freitas, F. C., Didonet, A. D., \& Didonet, C. C. G. M. (2007). Alimentos orgânicos - Oportunidades de mercado e desafios. Revista de Política Agrícola, 2(1), 4455.

Zanoli, R., \& Naspetti, S. (2002). Consumer motivations in the purchase of organic food: A meansend approach. British Food Journal, 104(8), 643-653. 